\title{
BMJ Open Development of a nomogram for the prediction of in-hospital mortality in patients with acute ST-elevation myocardial infarction after primary percutaneous coronary intervention: a multicentre, retrospective, observational study in Hebei province, China
}

\author{
Yudan Wang, ${ }^{1,2}$ Wenjing Wang, ${ }^{2}$ Shengqi Jia, ${ }^{1}$ Man Gao, ${ }^{1}$ Shihang Zheng, \\ Jiaqi Wang, ${ }^{3}$ Yi Dang, ${ }^{2}$ Yingxiao Li, ${ }^{2}$ Xiaoyong Qi (D) ${ }^{1,2}$
}

To cite: Wang Y, Wang W, Jia S, et al. Development of a nomogram for the prediction of in-hospital mortality in patients with acute STelevation myocardial infarction after primary percutaneous coronary intervention: a multicentre, retrospective, observational study in Hebei province, China. BMJ Open 2022;12:e056101. doi:10.1136/ bmjopen-2021-056101

- Prepublication history and additional supplemental material for this paper are available online. To view these files, please visit the journal online (http://dx.doi.org/10.1136/ bmjopen-2021-056101).

Received 06 August 2021 Accepted 18 January 2022

Check for updates

(C) Author(s) (or their employer(s)) 2022. Re-use permitted under CC BY-NC. No commercial re-use. See rights and permissions. Published by BMJ.

For numbered affiliations see end of article.

Correspondence to

Dr Xiaoyong Qi;

hbghqxy@126.com

\section{ABSTRACT}

Objectives To establish a clinical prognostic nomogram for predicting in-hospital mortality after primary percutaneous coronary intervention (PCl) among patients with ST-elevation myocardial infarction (STEMI).

Design Retrospective, multicentre, observational study.

Setting Thirty-nine hospitals in Hebei province.

Participants Patients with STEMI who underwent PCl from January 2018 to December 2019.

Interventions A multivariable logistic regression model was used to identify the factors associated with in-hospital mortality, and a nomogram was established using these factors. The performance of the nomogram was evaluated by the discrimination, calibration and clinical usefulness.

Primary and secondary outcome measures The outcome was the factors associated with in-hospital mortality.

Results This study included 855 patients, among whom 223 died in hospital. Age, body mass index, systolic pressure on admission, haemoglobin, random blood glucose on admission, ejection fraction after $\mathrm{PCl}$, use aspirin before admission, long lesions, thrombolysis in myocardial infarction flow grade and neutrophils/ lymphocytes ratio were independently associated with in-hospital mortality (all $p<0.05$ ). In the training set, the nomogram showed a C-index of 0.947 , goodness-of-fit of 0.683 and area under the receiver operating characteristic curve (AUC) of 0.947 (95\% $\mathrm{Cl} 0.927$ to 0.967$)$. In the testing set, the $\mathrm{C}$-index was 0.891 , goodness-of-fit was 0.462 and AUC was 0.891 (95\% Cl 0.844 to 0.939 ). The results indicate that the nomogram had good discrimination and good prediction accuracy and could achieve a good net benefit.

Conclusions A nomogram to predict in-hospital mortality in patients with STEMI after PCI was developed and validated in Hebei, China and showed a satisfactory performance. Prospective studies will be necessary to confirm the performance and clinical applicability and practicality of the nomogram.
Strengths and limitations of this study

This is a multicentre study, included 39 tertiary centres and 855 patients, including $223(26.1 \%)$ patients who died in the hospital.

- The data were obtained retrospectively, and some patients died during the percutaneous coronary intervention, which may have led to some missing information.

- Prospective studies will be necessary to confirm the performance and clinical applicability and practicality of the nomogram.

\section{INTRODUCTION}

ST-segment elevation myocardial infarction (STEMI), a type of coronary artery disease $(\mathrm{CAD})$, is a common clinical emergency and critical illness. ${ }^{1}$ STEMI is most often caused by plaque rupture of an atherosclerotic lesion in the affected (culprit) coronary artery followed by total occlusion of the vessel lumen with a thrombus. ${ }^{23}$ Common risk factors for STEMI are tobacco abuse, dyslipidaemias, hypertension, diabetes mellitus and a family history of CAD. ${ }^{4}$ In recent years, with well-established diagnosis and treatment guidelines, continuous standardisation of the treatment of STEMI, increasing evidence of determinants of patient prognosis and development of emerging technologies, there has been a considerable reduction in STEMI mortality; still, mortality seems to have plateaued. ${ }^{3}$

Primary percutaneous coronary intervention (PCI) has become the preferred reperfusion strategy in patients with STEMI according 
to the current clinical guidelines for STEMI in the USA and Europe ${ }^{56}$ Nevertheless, even if such patients receive timely PCI and/or appropriate antiplatelet drugs, the prognosis is still unsatisfying, and a substantial number of STEMI patients still die in-hospital after PCI (about $6 \%) .{ }^{378}$ Therefore, there is still room for improving the short-term outcomes of these patients on top of a timely PCI.

Various studies examined the risk factors of short and long-term mortality of STEMI patients after PCI. ${ }^{9-11}$ Guidelines encourage the use of clinical scores such as the thrombolysis in myocardial infarction (TIMI) or The Global Registry of Acute Coronary Events for STEMI to assess early and long-term risk. ${ }^{56}{ }^{12}$ Several biomarkers have been reported to confer independent prognostic information after STEMI, including Cardiac Troponin, brain natriuretic peptide (BNP), amino-terminal proBNP, and D-dimer. ${ }^{13-16}$ Unfortunately, these studies often exclude patients with advanced age, liver or kidney dysfunction, and other comorbidities and complications. The generalisability of those studies is limited, and it is difficult to summarise and reflect the real-world treatment situation comprehensively.

Therefore, the objective of this study was to develop a clinical nomogram for predicting in-hospital mortality of patients with STEMI after PCI. The results could provide clinical guidance and improve the outcome of STEMI patients.

\section{PATIENTS AND METHODS}

\section{Study design and patients}

This multicentre, retrospective, observational study included STEMI patients treated with PCI at 39 PCI hospitals in Hebei province from January 2018 to December 2019. The cohort was divided into a training set and a time-independent validation set. The training set refers to the use of modelled data to verify the predictive effect of the model, while test set is to use another group of patients' data (namely external data) to verify the prediction accuracy of the model. The training set patients enrolled from January 2018 to December 2018 and the testing set patients enrolled from January 2019 to December 2019.

All patients met the diagnostic criteria of acute STEMI based on their symptoms and/or ECG, myocardial damage markers and other test results and underwent primary PCI according to the 2017 ESC guidelines for the management of STEMI, ${ }^{5}$ namely with persistent chest discomfort or other symptoms suggestive of ischaemia and ST-segment elevation in at least two contiguous leads. Patients with non-STEMI or unstable angina or STEMI patients who did not undergo PCI were excluded. Patients who were readmitted to the hospital for revascularisation of non-culprit vessel were also excluded. The treatment strategy after PCI of surviving patients is determined by the doctor in charge in accordance with relevant guidelines.
The study was conducted according to the tenets of the Declaration of Helsinki for Medical Research Involving Human Subjects and Good Clinical Practice.

\section{Patient and public involvement}

Patients or the public were not involved in the design or reporting or dissemination plans of our research as this study is a retrospective, observational study.

\section{Definitions}

Long lesions was defined as the stenosis that has as $\geq 50 \%$ reduction and more than $20 \mathrm{~mm}$ in luminal diameter. ${ }^{17}$

Residual stenosis was defined as $>30 \%$ residual stenosis of the target lesion after PCI.

Bleeding was defined as a composite of major bleeding according to Bleeding Academic Research Consortium Definition for Bleeding type 3 or 5 , but was not related to coronary-artery bypass grafting. ${ }^{18}$

Major adverse cardiovascular event (MACE) refers to a combined or composite clinical endpoint that is used for outcome evaluations in clinical trials for cardiovascular research.

Acute coronary syndrome (ACS) is a term used to describe a range of conditions associated with sudden, reduced blood flow to the heart.

\section{Data collection}

Demographics (age, sex, and body mass index (BMI)), medical history (hypertension, diabetes mellitus, atrial fibrillation (AF), hyperlipidaemia and family history of $\mathrm{CAD}$, stroke, renal failure and peripheral artery disease), angiographic characteristics and information of cardiac procedures (disease condition, TIMI flow grade, number of stents, use of intra-aortic balloon pump (IABP), use of temporary pacemaker, use of ventilator and whether there was no-reflow, coronary perforation and cardiac arrest), medications on admission (antiplatelet agents, $\beta$-blockers, nitrate, ACE inhibitors (ACEI), angiotensin receptor blockers (ARB) and statin), biochemical markers (neutrophils/lymphocytes, N/L ratio), haematocrit, haemoglobin (HGB), platelets (PLT) and random blood glucose on admission) and left ventricular ejection fraction (LVEF) after PCI were extracted from the medical charts. All treatments were according to the current guidelines.

\section{Nomogram construction}

Demographics, medical history, vital signs before and after PCI, and auxiliary examinations were evaluated using univariable logistic regression. Variables with $p<0.05$ in the univariable logistic analyses were included for multivariable logistic analysis and nomogram construction. Receiver operator characteristic (ROC) curve analysis was used to quantify the prediction performance of the nomogram. A calibration curve was used to evaluate the calibration of the nomogram, and its goodness-of-fit was assessed using the Hosmer-Lemeshow test. Finally, the clinical usefulness of the nomogram was accessed using a decision curve analysis (DCA). 


\section{Statistical analysis}

Statistical analyses were performed using R V.4.0.3 (R Foundation for Statistical Computing) with RStudio (V.1.3.959; RStudio, Auckland, New Zealand). R packages used in this study were rms, reader, tableone, pROC, ResourceSelection and rmda. The predictive accuracy of the nomogram was measured using the C-statistic (Bootstrap method, 1000 times). Calibration was evaluated using the Hosmer-Lemeshow statistic. Categorical variables were presented as frequencies with percentages, normally distributed continuous variables as means $\pm \mathrm{SD}$, and other data as medians with IQRs. Categorical variables were compared using the $\chi^{2}$ test or Fisher's test if the expected cell count was $<5$. Student's t-test was used to compare normally distributed continuous variables. Otherwise, the Mann-Whitney U test was used. The significance level was set at 0.05 , and two-sided tests were used.

\section{RESULTS}

\section{Characteristics of the patients}

The whole study population consisted of 855 patients diagnosed with STEMI and who underwent PCI, including 396 in the training set (132 (33.3\%) dead patients and, 264 $(66.7 \%)$ survivors) and 459 (91 (19.8\%) dead patients, 368 $(80.2 \%)$ survivors) in the test set (figure 1). The clinical characteristics, including demographic, medical history, angiographic characteristics and information of cardiac procedures, medications and biochemical markers, are summarised in online supplemental table 1 . The clinical characteristics selected as predictors for the nomogram are summarised in table 1 . The patients who died in the hospital were older $(69.8 \pm 10.2$ vs $60.2 \pm 12.6$ years, $\mathrm{p}<0.01)$, more likely to be women $(32.7 \%$ vs $21.5 \%, \mathrm{p}<0.01)$ and more had complications like hypertension, $\mathrm{AF}$ and hyperlipidaemia. The hospital stay was $8.51 \pm 5.11$ days in the training set and $8.32 \pm 4.70$ days in the test set.

\section{Nomogram construction}

According to the multivariable logistic analysis, 10 variables meet the threshold of $\mathrm{p}<0.05$. Age (OR 1.069, 95\% CI 1.048 to $1.092, \mathrm{p}=0.049$ ), BMI (OR $0.55,95 \%$ CI 0.31 to $0.87, \mathrm{p}=0.019$ ), SBP on admission (OR $0.92,95 \%$ CI 0.86 to $0.97, \mathrm{p}=0.009$ ), HGB (OR $0.85,95 \%$ CI 0.73 to 0.97 , $\mathrm{p}=0.017$ ), random blood glucose on admission (OR 1.53, 95\% CI 1.13 to 2.21, $\mathrm{p}=0.011$ ), EF after PCI (OR 0.89, $95 \%$ CI 0.80 to $0.97, \mathrm{p}=0.015)$, aspirin (OR $0.001,95 \%$ CI 0.009 to $0.04, \mathrm{p}=0.001$ ), $\mathrm{N} / \mathrm{L}$ ratio (OR $1.34,95 \%$ CI 1.12 to $1.69, \mathrm{p}=0.004$ ), long lesions (OR 2.00, $95 \% \mathrm{CI} 1.310$ to $3.084, \mathrm{p}<0.001)$ and TIMI flow grade (OR 2.15, $95 \%$ CI 1.242 to $3.900, p=0.008$ ) were independently associated with in-hospital mortality after PCI of STEMI (table 2). The nomogram is shown in figure 2. The formula for calculating the total point of the nomogram is showed below:

S core $=15.5628+0.0320 \times$ a g e $-0.2991 \times \mathrm{BM} \mathrm{I}-$ $0.0184 \times \mathrm{SBP}-0.0331 \times \mathrm{HGB}+0.3663 \times$ random glucose on admission-0.1188 $\times$ LVEF after PCI$4.7705 \times$ aspirin $+0.0521 \times \mathrm{N} / \mathrm{L}$

ratio-2.4688×long leisions $+5.1018 \times$ TIMI flow grade.

\section{Evaluation of the nomogram}

In the training set, the C-index was 0.947, indicating that the prediction model was valuable in clinical practice (figure 3A). The value of goodness-of-fit was 0.683, indicating a good prediction accuracy. The ROC curve is shown in figure $4 \mathrm{~A}$ (area under the curve, $\mathrm{AUC}=0.947$, $95 \%$ CI 0.927 to 0.967 ). Figure 5A shows the DCA curve for the training set, indicating that the nomogram had a high overall net benefit in predicting in-hospital mortality after PCI treatment.

In the testing set, the $\mathrm{C}$-index was 0.891 . Figure $3 \mathrm{~B}$ shows the calibration curve, and the value of goodness-of-fit was 0.462 . The ROC curve is shown in figure $4 \mathrm{~B}$ (AUC $0.891,95 \%$ CI 0.844 to 0.939 ). The DCA curve is shown in figure 5B. The results of the testing set indicate that the nomogram had good discrimination and good prediction accuracy which could achieve a good net benefit.

\section{DISCUSSION}

In this study, a relatively accurate clinical nomogram was constructed, which demonstrated adequate discrimination and calibration power to provide an individualised estimation for the in-hospital mortality in STEMI patients after PCI. For the construction of the nomogram, 10 significant predictors were screened by multivariable logistic analysis.

In our study, age was an independent risk factor of STEMI patients, in accordance with other analyses of STEMI patients and underlining the high-risk profile of elderly patients, as they usually present with more risk factors and comorbidities than younger patients, ${ }^{19}{ }^{20}$ such as the higher prevalence of renal insufficiency, lower LVEF. High mortality in the older patients might also result from end-organ dysfunction, competing risks might also offset the benefits from reperfusion, such that successful outcomes are more dependent on overall health issues. Therefore, for older patients, some authors have also questioned the benefit of reperfusion therapy. ${ }^{21}$

For previous view, obesity increases insulin resistance, worsens plasma lipid profiles and increases arterial blood pressure, which has adverse effects on patients with CAD through the indirect effects of other risk factors (such as hypertension, impaired glucose tolerance and hyperinsulinaemia). ${ }^{22}$ Therefore, obese patients demonstrate greater adverse left ventricle (LV) remodelling and more impaired LV deformation after STEMI compared with those similar infarct characteristics but normal BMI. ${ }^{23}{ }^{24}$ Interestingly, some studies have shown the so-called 'obesity paradox', whereby obesity is related to better clinical outcomes ${ }^{22}{ }^{25-27}$ consistent with this study. Fukuoka $e t a l^{28}$ reported that this phenomenon is only observed in elderly patients, not in younger patients, so the influence of BMI on risk factors for death might vary 


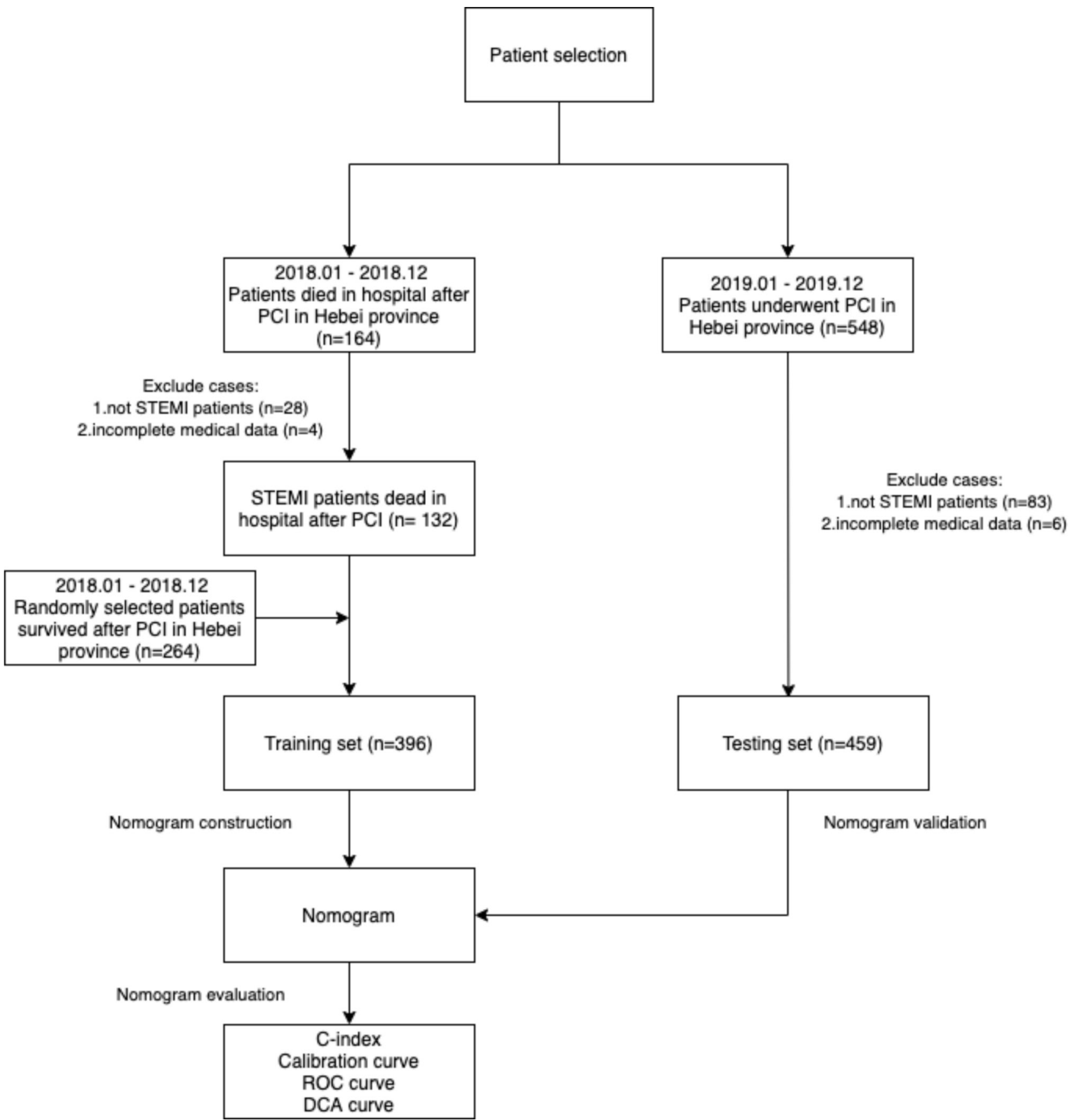

Figure 1 Flow chart illustrating the process of patient selection. DCA, decision curve analysis; $\mathrm{PCl}$, percutaneous coronary intervention; ROC, receiver operator characteristic; STEMI, ST-elevation myocardial infarction.

with age. Nevertheless, obesity is currently recognised as a risk factor for the long-term prognosis of patients with $\mathrm{CAD}$, and it is worth recommending maintaining BMI at a normal level. ${ }^{28}$

Acute stress has been shown to regulate the immune response of lymphocytes and reduce the number of peripheral blood lymphocytes. The smaller the value, the higher the body's stress level. Therefore, the N/L ratio, an index for systemic inflammatory status, usually increases after STEMI. ${ }^{29-31}$ Pan $e t a l^{32}$ demonstrated the independent association between increased $\mathrm{N} / \mathrm{L}$ ratio and short-term mortality in STEMI patients after PCI.
The predictive value of the $\mathrm{N} / \mathrm{L}$ ratio may be based on the following reasons. Stimulated neutrophils release superoxide radicals, proteolytic enzymes, and arachidonic acid metabolites that increase the infarct size and lead to cardiac electrical instability by damaging endothelial cells, activating coagulation cascade, aggregation of leukocytic cells and plugging the microarteries. ${ }^{33}$ These actions will participate in the extension of the areas of myocardial infarction, impaired epicardial and microvascular perfusion, no-reflow/slow flow during PCI, decreased LVEF and postinfarction death. ${ }^{34-36}$ 


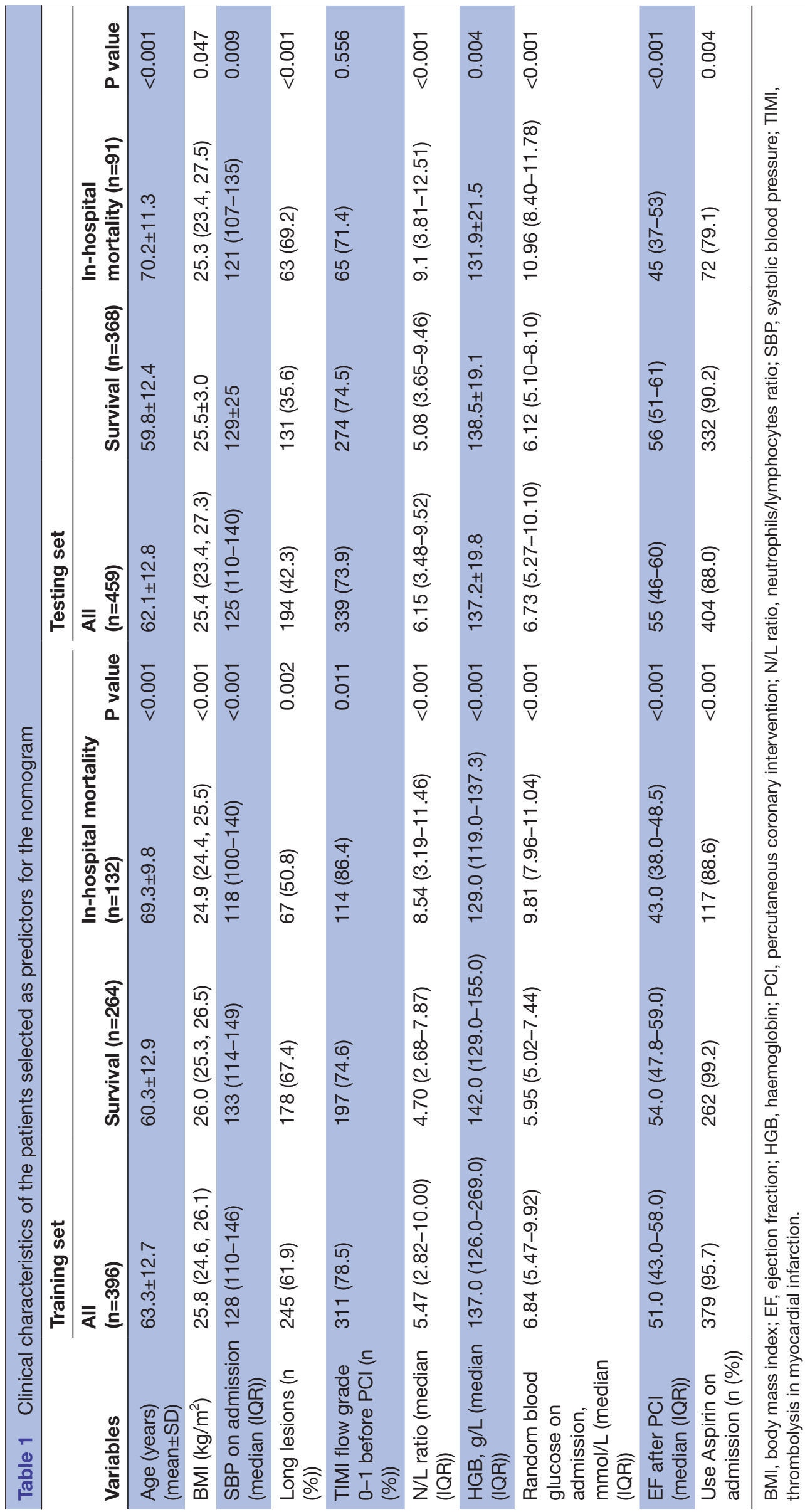


Table 2 Variables selected as predictors for the nomogram according to the multivariable logistic analysis

\begin{tabular}{|c|c|c|c|c|c|c|}
\hline \multirow[b]{2}{*}{ Variables } & \multicolumn{3}{|c|}{ Univariate analysis } & \multicolumn{3}{|c|}{ Multivariate analysis } \\
\hline & OR & $95 \% \mathbf{C l}$ & P value & OR & $95 \% \mathbf{C l}$ & $P$ value \\
\hline Age & 1.07 & 1.05 to 1.09 & $<0.001$ & 1.07 & 1.05 to 1.09 & 0.049 \\
\hline SBP on admission & 0.98 & 0.97 to 0.99 & $<0.001$ & 0.92 & 0.86 to 0.97 & 0.009 \\
\hline HGB & 0.97 & 0.95 to 0.98 & $<0.001$ & 0.85 & 0.73 to 0.97 & 0.017 \\
\hline EF after $\mathrm{PCl}$ & 0.91 & 0.88 to 0.93 & $<0.001$ & 0.89 & 0.80 to 0.97 & 0.015 \\
\hline Use aspirin before admission & 0.06 & 0.01 to 0.22 & $<0.001$ & 0.01 & 0.009 to 0.04 & 0.001 \\
\hline $\mathrm{N} / \mathrm{L}$ ratio & 1.08 & 1.04 to 1.12 & $<0.001$ & 1.34 & 1.12 to 1.69 & 0.004 \\
\hline Long lesions & 0.50 & 0.32 to 0.76 & 0.001 & 2.00 & 1.31 to 3.08 & $<0.001$ \\
\hline TIMI flow grade $0-1$ before $\mathrm{PCI}$ & 2.15 & 1.24 to 3.90 & $<0.001$ & 2.15 & 1.24 to 3.90 & 0.008 \\
\hline
\end{tabular}

BMI, body mass index; EF, ejection fraction; HGB, haemoglobin; PCI, percutaneous coronary intervention; N/L ratio, neutrophils/lymphocytes ratio; SBP, systolic blood pressure; TIMI, thrombolysis in myocardial infarction.

The acute phase of STEMI leads to insulin resistance, glucose intolerance and hyperglycaemic. The elevated levels of cytokines, growth hormone, glucagon and cortisol result in increased hepatic glucose production. Hepatic glycogenolysis is further enhanced by catecholamines that also inhibit glycogenesis and stimulate the release of free fatty acids (FFAs). High concentrations of FFAs will increase myocardial oxygen requirement, reduce myocardial activity and contractility, impair calcium homeostasis and increase the production of free radicals, leading to an increased risk of myocardial damage and arrhythmias. ${ }^{37-40}$ Thus, acute hyperglycaemic might contribute to a poor outcome. Previous studies reported that higher admission glucose was strongly correlated with larger infarct size, lower LVEF, and increased mortality risk in patients with and without diabetes. ${ }^{412}$ Exercise training, dietary modifications, and intervention in the hospital, such as tight glycaemic control during early PCI or at least within 24 hours after STEMI might reduce the mortality risk in such patients. ${ }^{4344}$

Lower admission HGB was associated with higher in-hospital mortality when analysed as a continuous variable (OR $0.966,95 \%$ CI 0.954 to 0.978 ). In the study from Shacham et $a l,{ }^{45}$ they revealed the longer total ischaemic time, namely an ongoing inflammatory process, the lower admission HGB levels. HGB levels and inflammation are closely related. In patients with STEMI, inflammation block occurs, that is, an abundance of hepcidin leads to poor uptake of iron from the gastrointestinal tract, iron sequestration in macrophages, little iron recycling to the erythron for red-cell production and microcytic anaemia, which can cause a lower HGB level. ${ }^{46}$

Because of the important role of PLT in thrombus formation, this study showed that prior aspirin use could reduce in-hospital mortality of STEMI patients after PCI, as supported by earlier clinical trials. ${ }^{478}$ Weidmann $e t a t^{48}$ provided evidence suggesting that pre-existing treatment with aspirin favourably affected the clinical presentation, infarct size and degree of inflammation of patients with STEMI. Yonetsu et $a l^{49}$ reported that aspirin inhibits PLT aggregation and therefore reduces the probability of an occluding clot on top of a ruptured plaque and, conversely, the occurrence of STEMI.

Previous studies indicated that lesion length is associated with long-term adverse events after PCI and is an important risk factor for restenosis and stent thrombosis. ${ }^{5-52}$ A longer lesion, with its greater plaque burden, is conceived to provide a major source of smooth muscle cells that will then proliferate to form neointima. Atherosclerotic plaques have often been found to demonstrate an increased expression of isoforms characteristic of activated smooth muscle cells that are not present in normal vasculature. ${ }^{53}$ Still, there are few studies on lesion length and in-hospital mortality, and further studies are still necessary. Preprocedural reperfusion might have a prognostic value. ${ }^{54} \mathrm{~A}$ strong relationship exists between preprocedural TIMI flow grade and infarct size and predischarge LVEF. ${ }^{55} \mathrm{SBP}$ is a critical factor, and hypotension was associated with a decrease in survival. ${ }^{56}$

In our multivariate analysis, the higher Killip Class is not a predictor of in-hospital mortality in STEMI patients. However, in a recent work from Del Buono et $a l l^{57}$ it was proved that a higher Killip Class is an independent risk factor for MACE events and in-hospital mortality in patients with anterior myocardial infarction. This is the first study including only patients with STEMI in the anterior location and excluding patients with history of cardiovascular diseases in order to reduce the heterogeneity of the population enrolled. This may be one of the reasons for the inconsistency of the two studies. Nevertheless, Killip classification is a simple and convenient clinical tool that can quickly stratify the risk of ACS patients and is likely to become an independent predictor of longterm follow-up results again.

The nomogram is a simple and intuitive representation of the mathematical model. ${ }^{58}$ In addition, to be of 
Points

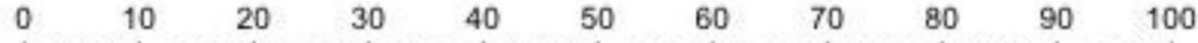

Age

पागयागा1ा

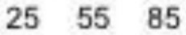

BMI

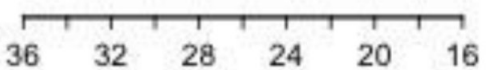

pre_SBP

$\begin{array}{llll}240 & 180 & 120 & 60\end{array}$

HGB

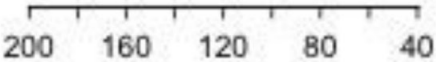

pre_Glu

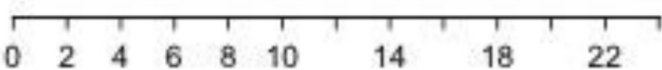

post_EF

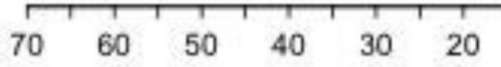

pre_Aspirin

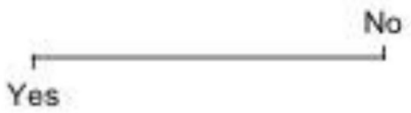

NLR

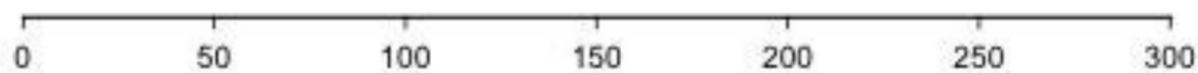

long lesions

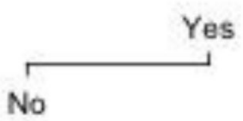

pre_TIMI

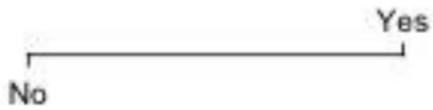

Total Points

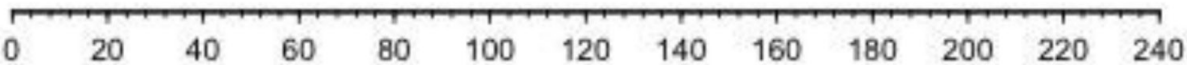

\section{Risk}

Figure 2 The nomogram for the prediction of in-hospital mortality in patients with acute ST-elevation myocardial infarction after primary $\mathrm{PCl}$. BMI, body mass index; EF, ejection fraction; HGB, haemoglobin; N/LR, neutrophils/lymphocytes ratio; PCI, percutaneous coronary intervention; SBP, systolic blood pressure; TIMI, thrombolysis in myocardial infarction. 
A

Calibration Curve

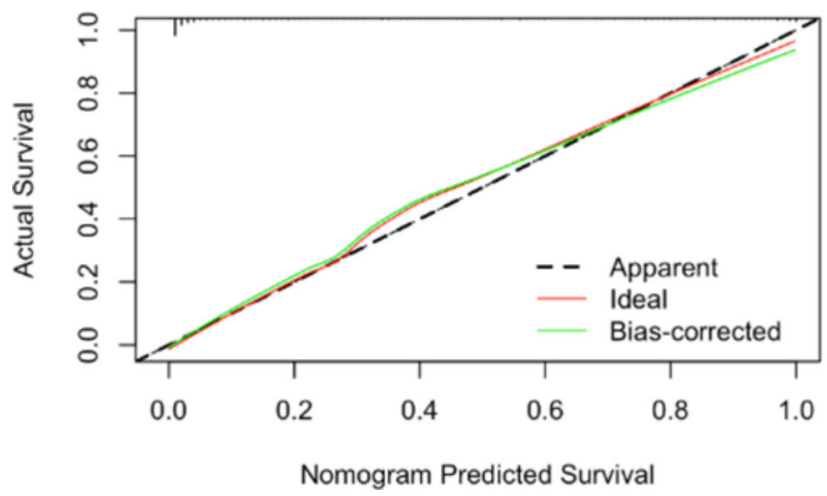

B

Calibration Curve

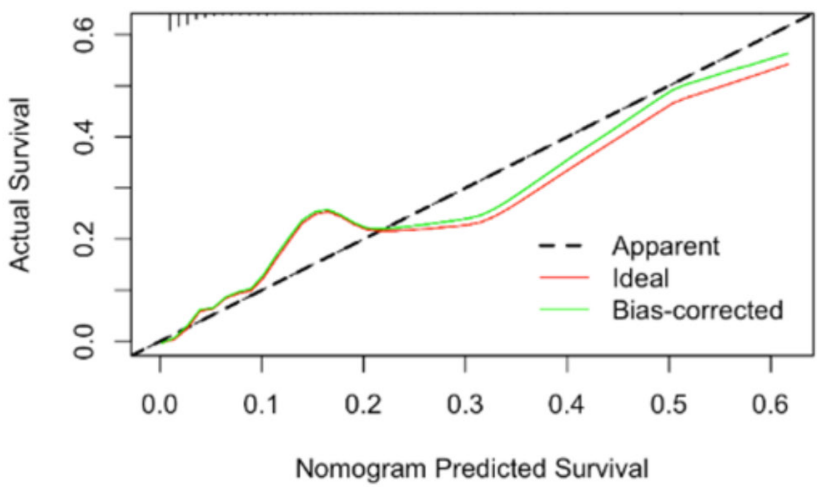

Figure 3 The calibration curves of the nomogram for the training set (A) and the testing set (B).

clinical usefulness in a routine setting, the nomogram must contain variables assessed in the routine clinical setting, which is the case with the nomogram developed here. It can simplify the statistical prediction model to the numerical probability of disease recurrence or death. The identification and stratification of patients becomes a simple tool with many advantages. The most prominent advantage is that it can predict individualised risks based on patient and disease characteristics. Second, it is easy to use and can help doctors develop individualised treatment plans. However, although the current clinical use of nomograms has increased, there are limited data on patient satisfaction or quality of life after it assists in medical decision making. In addition, although nomograms are widely used clinically, they are rarely evaluated prospectively to determine whether their use actually improves the prognosis of patients. ${ }^{59} 60$ Therefore, it remains to be explored how this risk model can be better applied to the clinic. The results indicate that the nomogram had good discrimination, well prediction accuracy and could achieve satisfactory net benefit. Another nomogram based on other variables (left main $\mathrm{CAD}$, grading of thrombus, TIMI classification, slow flow, use of IABP, use of $\beta$-blocker, use of ACEI/ARB, symptom-to-door time, symptom-to-balloon time, syntax score, LVEF, and CK-MB peak) also showed a high AUC for in-hospital mortality of patients with STEMI after PCI. ${ }^{61}$ Three main reasons fame justify the different predictors we found in our study: different research methods, the hospitals and time nodes that included patients are different and different statistical methods. Nevertheless, we are planning to combine the two parts of patients to get a more accurate risk model of in-hospital mortality.

Some study limitations should be mentioned: (1) This study has limitations that are inherent to retrospective observational studies. Many hospitals and doctors involved, which can lead to some missing information, such as liver enzymes, more information regarding the PCI procedure and other inflammatory index; (2) As the ischaemic time is shortened as much as possible, patients whose symptoms and/or ECG can be diagnosed are directly treated with PCI. Therefore, other potential risk factors in our study, such as LVEF before PCI, could not be included in the analyses. And some patients died during the PCI, resulting in the lack of postoperative treatment information. Further prospective studies are still necessary to confirm the performance of the clinical

B

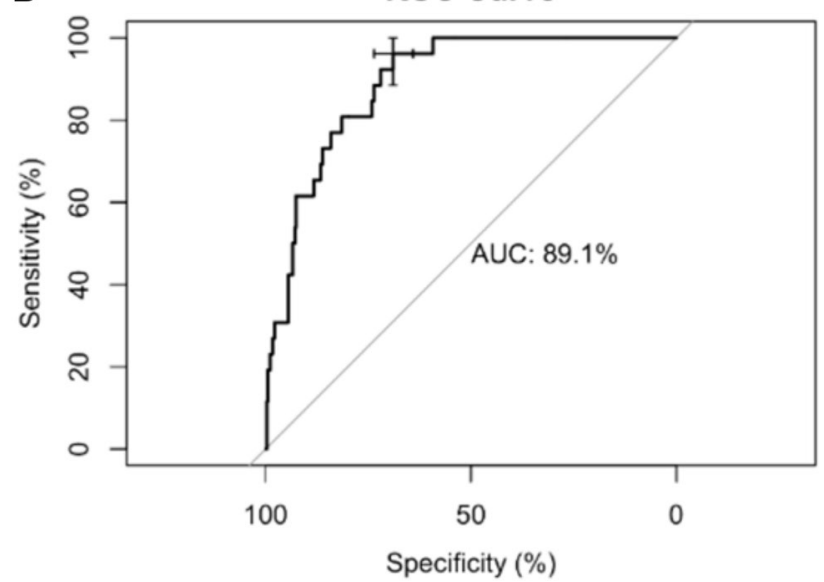

ROC Curve
A

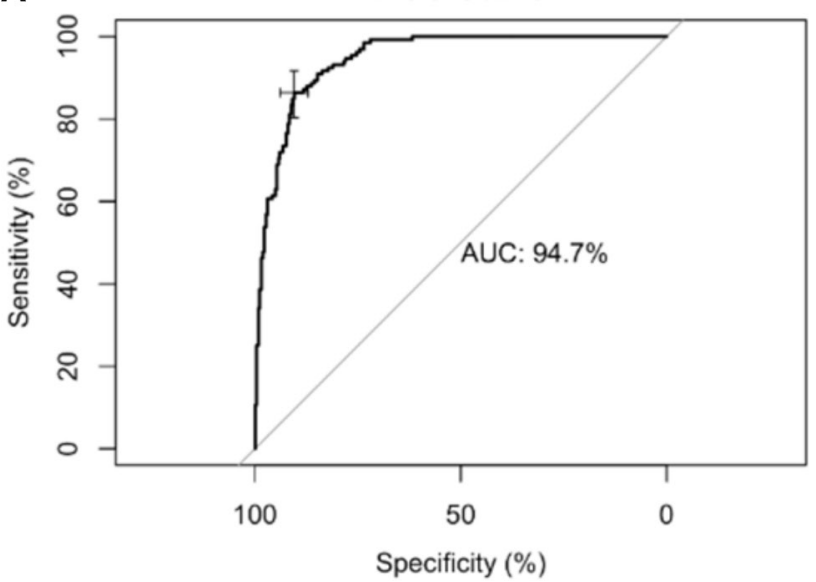

Figure 4 The received operating characteristics (ROC) curves of the nomogram for the training set $(A)$ and the testing set (B). AUC, area under the curve. 


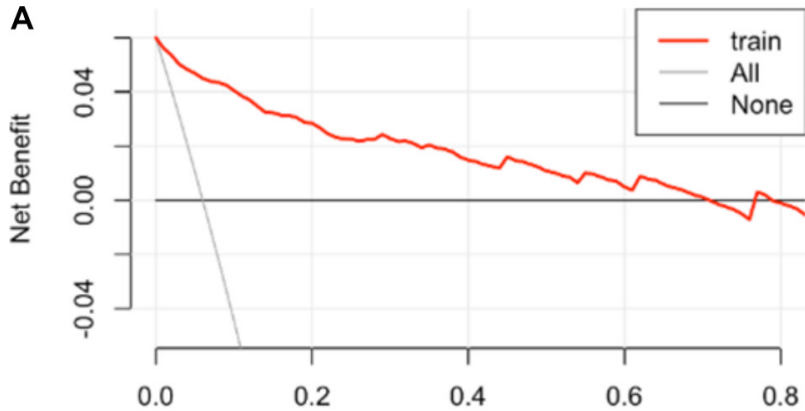

High Risk Threshold

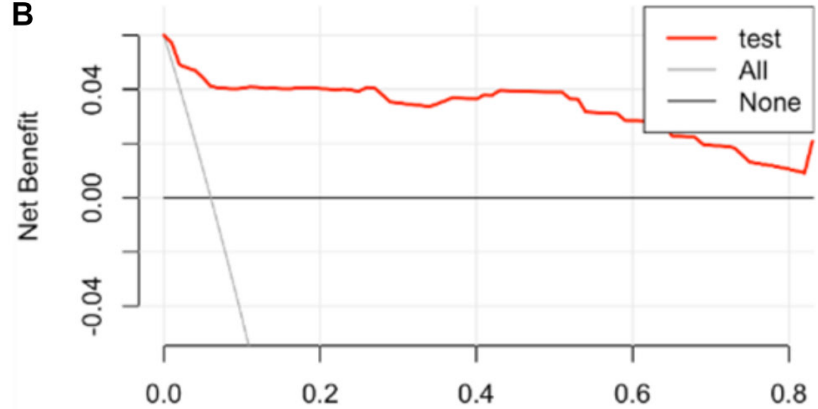

High Risk Threshold

Figure 5 The decision curve analysis for the risk model for the training set (A) and the testing set (B).

applicability in future investigations and verify the practicality in ICU.

In conclusion, a nomogram to predict in-hospital mortality in patients with STEMI after PCI was developed and validated in Hebei, China. The nomogram showed a satisfactory performance, with a C-index of 0.948. Thus, this nomogram might be a precisely individualised predictive tool for prognosis. However, additional studies are needed to confirm the performance and clinical applicability and practicality of the nomogram.

\section{Author affiliations}

${ }^{1}$ School of Graduate, Hebei Medical University, Shijiazhuang, Hebei, China ${ }^{2}$ Department of Cardiology Center, Hebei General Hospital, Shijiazhuang, Hebei, China

${ }^{3}$ School of Graduate, Hebei North University, Zhangjiakou, Hebei, China

Acknowledgements We acknowledge the members of the heart team at the participating centres for their efforts in collecting clinical data and ensuring the accuracy and completeness of the data. We thank the study participants and patient advisers for accepting to be part of the study for working tirelessly to make this work a reality.

Contributors YW, WW, MG and SZ carried out the studies, participated in collecting data, and drafted the manuscript. YW, YD and XQ performed the statistical analysis and participated in its design. SJ, JW and YL helped to draft the manuscript. $\mathrm{XQ}$ responsible for the overall content. All authors read and approved the final manuscript. $X Q$ acts as the guarantor.

Funding The authors have not declared a specific grant for this research from any funding agency in the public, commercial or not-for-profit sectors.

Competing interests None declared.

Patient consent for publication Consent obtained from next of kin.

Ethics approval This study involves human participants and was approved by the Ethics Committees of Hebei General Hospital (No. 202144). Participants gave informed consent to participate in the study before taking part.

Provenance and peer review Not commissioned; externally peer reviewed. Data availability statement № data are available.

Supplemental material This content has been supplied by the author(s). It has not been vetted by BMJ Publishing Group Limited (BMJ) and may not have been peer-reviewed. Any opinions or recommendations discussed are solely those of the author(s) and are not endorsed by BMJ. BMJ disclaims all liability and responsibility arising from any reliance placed on the content. Where the content includes any translated material, BMJ does not warrant the accuracy and reliability of the translations (including but not limited to local regulations, clinical guidelines, terminology, drug names and drug dosages), and is not responsible for any error and/or omissions arising from translation and adaptation or otherwise.

Open access This is an open access article distributed in accordance with the Creative Commons Attribution Non Commercial (CC BY-NC 4.0) license, which permits others to distribute, remix, adapt, build upon this work non-commercially, and license their derivative works on different terms, provided the original work is properly cited, appropriate credit is given, any changes made indicated, and the use is non-commercial. See: http://creativecommons.org/licenses/by-nc/4.0/.

ORCID iD

Xiaoyong Qi http://orcid.org/0000-0002-2938-2562

\section{REFERENCES}

1 O'Gara PT, Kushner FG, Ascheim DD, et al. 2013 ACCF/AHA guideline for the management of ST-elevation myocardial infarction: a report of the American College of cardiology Foundation/American heart association Task force on practice guidelines. Circulation 2013;127:e362-425.

2 Trost JC, Lange RA. Treatment of acute coronary syndrome: Part 2: ST-segment elevation myocardial infarction. Crit Care Med 2012;40:1939-45.

3 Vogel B, Claessen BE, Arnold SV, et al. St-Segment elevation myocardial infarction. Nat Rev Dis Primers 2019;5:39.

4 Authors/Task Force Members, Piepoli MF, Hoes AW, et al. 2016 European Guidelines on cardiovascular disease prevention in clinical practice: The Sixth Joint Task Force of the European Society of Cardiology and Other Societies on Cardiovascular Disease Prevention in Clinical Practice (constituted by representatives of 10 societies and by invited experts): Developed with the special contribution of the European Association for Cardiovascular Prevention \& Rehabilitation (EACPR). Eur J Prev Cardiol 2016;23:NP1--NP96.

5 Ibanez B, James S, Agewall S, et al. 2017 ESC guidelines for the management of acute myocardial infarction in patients presenting with ST-segment elevation: the task force for the management of acute myocardial infarction in patients presenting with ST-segment elevation of the European Society of cardiology (ESC). Eur Heart $J$ 2018;39:119-77.

6 O'Gara PT, Kushner FG, Ascheim DD, et al. 2013 ACCF/AHA guideline for the management of ST-elevation myocardial infarction: a report of the American College of cardiology Foundation/American heart association Task force on practice guidelines. J Am Coll Cardiol 2013;61:e78-140.

7 Li J, Li X, Wang Q, et al. St-Segment elevation myocardial infarction in China from 2001 to 2011 (the China PEACE-Retrospective acute myocardial infarction study): a retrospective analysis of hospital data. Lancet 2015;385:441-51.

8 Canto JG, Kiefe Cl, Rogers WJ, et al. Number of coronary heart disease risk factors and mortality in patients with first myocardial infarction. JAMA 2011;306:2120-7.

9 Cenko E, Yoon J, Kedev S, et al. Sex differences in outcomes after STEMI: effect modification by treatment strategy and age. JAMA Intern Med 2018;178:632-9.

10 Mehta SR, Wood DA, Storey RF, et al. Complete revascularization with multivessel PCl for myocardial infarction. $N$ Engl $\mathrm{J}$ Med 2019;381:1411-21.

11 Scholz KH, Maier SKG, Maier LS, et al. Impact of treatment delay on mortality in ST-segment elevation myocardial infarction (STEMI) patients presenting with and without haemodynamic instability: results from the German prospective, multicentre FITT-STEMI trial. Eur Heart J 2018;39:1065-74.

12 Levine GN, Bates ER, Bittl JA, et al. 2016 ACC/AHA guideline focused update on duration of dual antiplatelet therapy in patients with coronary artery disease: a report of the American College of 
Cardiology/American heart association Task force on clinical practice guidelines: an update of the 2011 ACCF/AHA/SCAI guideline for percutaneous coronary intervention, 2011 ACCF/AHA guideline for coronary artery bypass graft surgery, 2012 ACC/AHA/ACP/AATS/ PCNA/SCAI/STS guideline for the diagnosis and management of patients with stable ischemic heart disease, 2013 ACCF/AHA guideline for the management of ST-elevation myocardial infarction, 2014 AHA/ACC guideline for the management of patients with non-ST-elevation acute coronary syndromes, and 2014 ACC/ AHA guideline on perioperative cardiovascular evaluation and management of patients undergoing noncardiac surgery. Circulation 2016;134:e123-55.

13 Ottani F, Galvani M, Nicolini FA, et al. Elevated cardiac troponin levels predict the risk of adverse outcome in patients with acute coronary syndromes. Am Heart J 2000;140:917-27.

14 Sun T, Wang L, Zhang Y. Prognostic value of B-type natriuretic peptide in patients with acute coronary syndromes. Arch Med Res 2006;37:502-5.

15 Jaberg L, Toggweiler S, Puck M, et al. Prognostic value of N-terminal pro-B-type natriuretic peptide in patients with acute coronary syndromes undergoing left main percutaneous coronary intervention. Circ J 2011;75:2648-53.

$16 \mathrm{Yu}$ T, Jiao Y, Song J, et al. Hospital mortality in acute coronary syndrome: adjustment of grace score by D-dimer enables a more accurate prediction in a prospective cohort study. BMC Cardiovasc Disord 2019;19:252.

17 Sianos G, Morel M-A, Kappetein AP, et al. The SYNTAX score: an angiographic tool grading the complexity of coronary artery disease. Eurolntervention 2005;1:219-27.

18 Mehran R, Rao SV, Bhatt DL, et al. Standardized bleeding definitions for cardiovascular clinical trials: a consensus report from the bleeding academic research Consortium. Circulation 2011;123:2736-47.

19 Forman DE, Chen AY, Wiviott SD, et al. Comparison of outcomes in patients aged $<75,75$ to 84 , and $\geq 85$ years with ST-elevation myocardial infarction (from the ACTION Registry-GWTG). Am J Cardiol 2010;106:1382-8.

20 Rathod KS, Jones DA, Gallagher S, et al. Atypical risk factor profile and excellent long-term outcomes of young patients treated with primary percutaneous coronary intervention for STelevation myocardial infarction. Eur Heart $J$ Acute Cardiovasc Care 2016;5:23-32.

21 Haller PM, Jäger B, Farhan S, et al. Impact of age on short- and long-term mortality of patients with ST-elevation myocardial infarction in the Vienna STEMI network. Wien Klin Wochenschr 2018;130:172-81.

22 Lavie CJ, De Schutter A, Milani RV. Healthy obese versus unhealthy lean: the obesity paradox. Nat Rev Endocrinol 2015;11:55-62.

23 Payvar S, Kim S, Rao SV, et al. In-Hospital outcomes of percutaneous coronary interventions in extremely obese and normalweight patients: findings from the NCDR (national cardiovascular data registry). J Am Coll Cardiol 2013;62:692-6.

24 Winzap P, Davies A, Klingenberg R, et al. Diabetes and baseline glucose are associated with inflammation, left ventricular function and short- and long-term outcome in acute coronary syndromes: role of the novel biomarker Cyr 61. Cardiovasc Diabetol 2019;18:142.

25 Samanta R, Pouliopoulos J, Kumar S, et al. Influence of BMI on inducible ventricular tachycardia and mortality in patients with myocardial infarction and left ventricular dysfunction: the obesity paradox. Int J Cardiol 2018;265:148-54.

26 Lavie CJ, Milani RV, Ventura HO. Obesity and cardiovascular disease: risk factor, paradox, and impact of weight loss. J Am Coll Cardiol 2009;53:1925-32.

27 Samanta R, Narayan A, Kovoor P, et al. Influence of BMl on short and long-term outcomes in patients with STEMI and LV dysfunction. Heart Lung Circ 2020;29:361-7.

28 Fukuoka S, Kurita T, Dohi K, et al. Untangling the obesity paradox in patients with acute myocardial infarction after primary percutaneous coronary intervention (detail analysis by age). Int $\mathrm{J}$ Cardiol 2019;289:12-18.

29 Ayça B, Akın F, Celik O, et al. Neutrophil to lymphocyte ratio is related to stent thrombosis and high mortality in patients with acute myocardial infarction. Angiology 2015;66:545-52.

30 Machado GP, Araujo GNde, Carpes CK, et al. Comparison of neutrophil-to-lymphocyte ratio and mean platelet volume in the prediction of adverse events after primary percutaneous coronary intervention in patients with ST-elevation myocardial infarction. Atherosclerosis 2018;274:212-7.

31 Arbel Y, Shacham Y, Ziv-Baran T, et al. Higher neutrophil/lymphocyte ratio is related to lower ejection fraction and higher long-term allcause mortality in ST-elevation myocardial infarction patients. Can J Cardiol 2014;30:1177-82.
32 Pan W, Zhao D, Zhang C, et al. Application of neutrophil/lymphocyte ratio in predicting coronary blood flow and mortality in patients with ST-elevation myocardial infarction undergoing percutaneous coronary intervention. J Cardiol 2015;66:9-14.

33 Sen N, Afsar B, Ozcan F, et al. The neutrophil to lymphocyte ratio was associated with impaired myocardial perfusion and long term adverse outcome in patients with ST-elevated myocardial infarction undergoing primary coronary intervention. Atherosclerosis 2013;228:203-10.

34 Kaya MG, Akpek M, Lam YY, et al. Prognostic value of neutrophil/ lymphocyte ratio in patients with ST-elevated myocardial infarction undergoing primary coronary intervention: a prospective, multicenter study. Int J Cardiol 2013;168:1154-9.

35 Kirtane AJ, Bui A, Murphy SA, et al. Association of peripheral neutrophilia with adverse angiographic outcomes in ST-elevation myocardial infarction. Am J Cardiol 2004;93:532-6.

36 Sheridan FM, Cole PG, Ramage D. Leukocyte adhesion to the coronary microvasculature during ischemia and reperfusion in an in vivo canine model. Circulation 1996;93:1784-7.

37 Dandona P, Chaudhuri A, Ghanim H, et al. Insulin as an antiinflammatory and antiatherogenic modulator. J Am Coll Cardiol 2009;53:S14-20.

38 Devos P, Chioléro R, Van den Berghe G, et al. Glucose, insulin and myocardial ischaemia. Curr Opin Clin Nutr Metab Care 2006;9:131-9.

39 Young LH, Renfu Y, Russell R, et al. Low-Flow ischemia leads to translocation of canine heart GLUT-4 and GLUT-1 glucose transporters to the sarcolemma in vivo. Circulation 1997;95:415-22.

40 Khani S, Tayek JA. Cortisol increases gluconeogenesis in humans: its role in the metabolic syndrome. Clin Sci 2001;101:739-47.

41 Timmer JR, van der Horst ICC, Ottervanger JP, et al. Prognostic value of admission glucose in non-diabetic patients with myocardial infarction. Am Heart J 2004;148:399-404.

42 Planer D, Witzenbichler B, Guagliumi G, et al. Impact of hyperglycemia in patients with ST-segment elevation myocardial infarction undergoing percutaneous coronary intervention: the HORIZONS-AMI trial. Int J Cardiol 2013;167:2572-9.

43 Buchanan TA, Xiang AH, Peters RK, et al. Preservation of pancreatic beta-cell function and prevention of type 2 diabetes by pharmacological treatment of insulin resistance in high-risk Hispanic women. Diabetes 2002;51:2796-803.

44 Marfella R, Sasso FC, Siniscalchi M, et al. Peri-procedural tight glycemic control during early percutaneous coronary intervention is associated with a lower rate of in-stent restenosis in patients with acute ST-elevation myocardial infarction. J Clin Endocrinol Metab 2012;97:2862-71.

45 Shacham Y, Leshem-Rubinow E, Ben-Assa E, et al. Lower admission hemoglobin levels are associated with longer symptom duration in acute ST-elevation myocardial infarction. Clin Cardiol 2014;37:73-7.

46 Keel SB, Abkowitz JL. The microcytic red cell and the anemia of inflammation. N Engl J Med 2009;361:1904-6.

47 Brener SJ, Mehran R, Lansky AJ, et al. Pretreatment with aspirin in acute coronary syndromes: lessons from the acuity and HORIZONSAMI trials. Eur Heart J Acute Cardiovasc Care 2016;5:449-54.

48 Weidmann L, Obeid S, Mach F, et al. Pre-Existing treatment with aspirin or statins influences clinical presentation, infarct size and inflammation in patients with de novo acute coronary syndromes. Int J Cardiol 2019;275:171-8.

49 Yonetsu T, Lee T, Murai T, et al. Association between prior aspirin use and morphological features of culprit lesions at first presentation of acute coronary syndrome assessed by optical coherence tomography. Circ J 2017;81:511-9.

50 Claessen BE, Smits PC, Kereiakes DJ, et al. Impact of lesion length and vessel size on clinical outcomes after percutaneous coronary intervention with everolimus- versus paclitaxel-eluting stents pooled analysis from the spirit (clinical evaluation of the XIENCE V everolimus Eluting coronary stent system) and compare (second-generation everolimus-eluting and paclitaxel-eluting stents in real-life practice) randomized trials. JACC Cardiovasc Interv 2011;4:1209-15.

51 Kastrati A, Elezi S, Dirschinger J, et al. Influence of lesion length on restenosis after coronary stent placement. Am J Cardiol 1999;83:1617-22.

52 Choi IJ, Koh Y-S, Lim S, et al. Impact of the stent length on long-term clinical outcomes following newer-generation drug-eluting stent implantation. Am J Cardiol 2014;113:457-64.

53 Leclerc G, Isner JM, Kearney M, et al. Evidence implicating nonmuscle myosin in restenosis. Use of in situ hybridization to analyze human vascular lesions obtained by directional atherectomy. Circulation 1992;85:543-53.

54 Brodie BR, Stuckey TD, Hansen C, et al. Benefit of coronary reperfusion before intervention on outcomes after primary 
angioplasty for acute myocardial infarction. $A m \mathrm{~J}$ Cardiol 2000;85:13-18.

55 De Luca G, Ernst N, Zijlstra F, et al. Preprocedural TIMI flow and mortality in patients with acute myocardial infarction treated by primary angioplasty. J Am Coll Cardiol 2004;43:1363-7.

56 Lee KL, Woodlief LH, Topol EJ, et al. Predictors of 30-day mortality in the era of reperfusion for acute myocardial infarction. results from an international trial of 41,021 patients. GUSTO-I Investigators. Circulation 1995;91:1659-68.

57 Del Buono MG, Montone RA, Rinaldi R, et al. Clinical predictors and prognostic role of high Killip class in patients with a first episode of anterior ST-segment elevation acute myocardial infarction. $J$ Cardiovasc Med 2021;22:530-8.
58 Shariat SF, Karakiewicz PI, Godoy G, et al. Use of nomograms for predictions of outcome in patients with advanced bladder cancer. Ther Adv Urol 2009;1:13-26.

59 Balachandran VP, Gonen M, Smith JJ, et al. Nomograms in oncology: more than meets the eye. Lancet Oncol 2015;16:e173-80.

60 lasonos A, Schrag D, Raj GV, et al. How to build and interpret a nomogram for cancer prognosis. J Clin Oncol 2008;26:1364-70.

61 Gao N, Qi X, Dang Y, et al. Establishment and validation of a risk model for prediction of in-hospital mortality in patients with acute STelevation myocardial infarction after primary PCI. BMC Cardiovasc Disord 2020;20:513. 